\title{
Modeling and optimization of EDM machined AZ-91 Mg alloy using ANFIS-VIKOR method
}

\section{DOI : 10.36909/jer.ICCEMME.15747}

\author{
Jitendra Kumar, Shailesh Gautam, S. K. Rajput*, Tarun Soota
}

Department of Mechanical Engineering, Bundelkhand Institute of Engineering and Technology, Jhansi, 284128, India.

*Email: rajput_skumar@rediffmail.com; Corresponding Author.

\begin{abstract}
In this paper, machining of AZ-91 magnesium alloy was performed in EDM using different tool electrode $\left(\mathrm{Cu}, \mathrm{CuW}\right.$ and graphite). To perform experiments, Taguchi $L_{18}$ design of experiments was used to reduce experimental runs. EDM process parameters viz. polarity, current $\left(I_{p}\right)$, pulse-on-time $\left(T_{o n}\right)$, pulse-off-time $\left(T_{o f f}\right)$, and tool electrode material were considered in experimental design to measure the responses (MRR, $R_{a}$ ). Multi-input-singleoutput adaptive neuro fuzzy inference system (ANFIS) model was developed to predict responses, and predicted results were found in good agreement with the experimental results. Maximum MRR (0.089 g/min) was found at positive polarity, $I_{p}-5 \mathrm{~A}, T_{o n}-50 \mu \mathrm{s}, T_{\text {off }}-30 \mu \mathrm{s}$, and $\mathrm{Cu}$ tool, and minimum $R_{a}(0.08 \mu \mathrm{m})$ was at parameters positive polarity, $I_{p}-4 \mathrm{~A}, T_{o n}-30$ $\mu \mathrm{s}, T_{\text {off }}-20 \mu \mathrm{s}$, and $\mathrm{Cu}$ tool. Relative errors between experiential results and ANFIS predicted results were $1.17 \%$ for MRR, and $2.20 \%$ for $R_{a}$. Multi response optimization ANFISVIKOR method was successfully developed and gave compromise solution for MRR and $R_{a}$ corresponding to minimum ANFIS-VIKOR index $\left(Q_{i}\right)$. A factor level analysis was performed to evaluate optimal factor combination for ANFIS-VIKOR index, and it shows that current $\left(I_{p}\right)$ have a significant effect.
\end{abstract}

Keywords: ANFIS-VIKOR; AZ-91 magnesium alloy; EDM; MRR; $R_{a}$. 


\section{INTRODUCTION}

Electric discharge machine (EDM) is a non-conventional material elimination machine used to machine electrically conductive material submerged in dielectric fluid. EDM produced complex shapes and structures that cannot be easily machined by conventional machining ( $\mathrm{Li}$ et al., 2003; Li et al., 2002; Amorim et al., 2005). In EDM, a chain of continuous sparks were produced when two electrodes comes closer to each other (DiBitonto et al., 1989). During machining, controlled process parameters resulted higher surface roughness $\left(R_{a}\right)$, good precision, accuracy, small electrode wear, high material removal etc. (Lee et al., 2001; Ho et al., 2003). The parameters that affect the machining efficiency and performance are applied voltage $(V)$, on-time $\left(T_{o n}\right)$, off-time $\left(T_{o f f}\right)$, duty cycle $(\tau)$, peak current $\left(I_{p}\right)$, dielectric pressure, tool material, interelectrode-gap, machining-time, polarity etc.

Magnesium alloys are lightweight alloys so it is extensibility used in the aircraft industries. It has outstanding physical properties i.e. low density, bio-compatibility, good damping and strength to weight ratio, thus this alloy is favourable in the field of aerospace, transport, electronics, and biomedical industries (Song et al., 2020; Luo et al., 2019). Application areas of $\mathrm{Mg}$ alloys give the motivation to work with EDM for high precision and accuracy (Ali et al., 2015; Yeganeh et al., 2015). Razak et al. (2016) has been machined AZ-31 Mg alloy using EDM. Four processing parameters viz. voltage, $T_{o n}, T_{\text {off }}$ and $I_{p}$ have been used to measure surface roughness $\left(R_{a}\right)$ and concluded that $T_{o n}$ has greatest impact on $R_{a}$.

In EDM, tool electrode properties and geometry enhanced the machinability of the work material (Bhaumik and Maity, 2018; Zhang et al., 2016). Since large number of parameters are associated in EDM, thus to reduce flaws in experiments a specific design and analysis (DOE) are needed. Taguchi method gives a systematics procedure with minimum number of experiments, and also used to optimize the characteristics of single response (Khan et al., 2020; Ramaswamy et al., 2020). Multi-response optimization techniques viz. RSM, grey 
relation analysis (GRA), VIKOR, TOPSIS facilitates multiple response optimizations. GRA has found a broad application to determine optimal parameters for machining response (Kumar et al., 2010; Kumar et al., 2018). The problems that cannot be solved by classical methods, are solved by artificial intelligence (AI) tool. AI is a popular tool in science and technology. The adaptive neuro fuzzy inference system (ANFIS) is an integration of artificial neural network (ANN) and fuzzy inference system (FIS). ANFIS reduced relative error by improving membership function of FIS (Rodic et al., 2020; Singh et al., 2020; Maher et al., 2015). Manikandan et al. (2019) developed grey based ANFIS model to predict grey relation grade for machined LM6/SiC/Dunite. The developed grey-ANFIS model had $0.117 \%$ relative error with experiment results. To predict recast layer thickness, Dhaker et al. (2019) developed ANFIS model for laser drilled Inconel 718 and reported relative error of 5\%. ANFIS is a multi-input single output predictor model, thus to optimize multi-response, a multi-criteria-decision-making (MCDM) VIKOR (Vlse Kriterijumska Optimizacija Kompromisno Resenje) method was integrated with ANFIS. VIKOR gives compromise solution to the response in maximum group utility with minimum regret measure (Tong et al., 2007; Singaravel et al., 2020)

It was observed from the literature that significant amount of work on machining of different materials using EDM are available, but there is scarcity of literature on machining of AZ-91 Mg alloy. Thus, it is necessary to perform systematic study of machining AZ-91 Mg alloy using different processing parameters in EDM. In this work, AZ-91 magnesium alloy was machined with ZNC-EDM, to explore the effect of different EDM process parameters (tool material, current, pulse-on-time, pulse-off-time, polarity) on different aspects of performance characteristics such as MRR and $R_{a}$. Also, to predict responses using ANFIS model, followed by integration of VIKOR method to find the optimal response parameters (MRR and $R_{a}$ ). 


\section{METHODOLOGY}

\section{Measurement of responses}

MRR is a desire response in machining and mathematically represented by Equation (1).

$$
M R R=\frac{W f-W i}{\rho \times \mathrm{Tm}},(\mathrm{g} / \mathrm{min})
$$

Where $W_{i}$, and $W_{f}$, are the weight of specimen before, and after machining respectively, and $T_{m}$ is machining time.

Surface roughness measures the smoothness and highly affected by process parameters during machining in EDM. The value of $R_{a}$ is determined by Equation (2).

$$
R a=\frac{1}{M} \int_{0}^{M} Z x(d x)(\mu m)
$$

where, $M$ is evaluation length, and $Z_{x}$ is the height between peaks and valleys.

\section{ANFIS modeling and optimization using ANFIS-VIKOR method}

Adaptive neuro-fuzzy inference system (ANFIS) was introduced by Jang (Jang, 1993). First order Sugeno model was developed to define the process parameters and hybrid learning rule was applied to enhance the fuzzy system constraints. Sugano fuzzy model (also called Tsukamoto fuzzy model) was familiarized with a systematic strategy for constructing the fuzzy instructions for input-output pair. The construction of two inputs, single output firstorder ANFIS Sugeno system is shown in Figure 1.

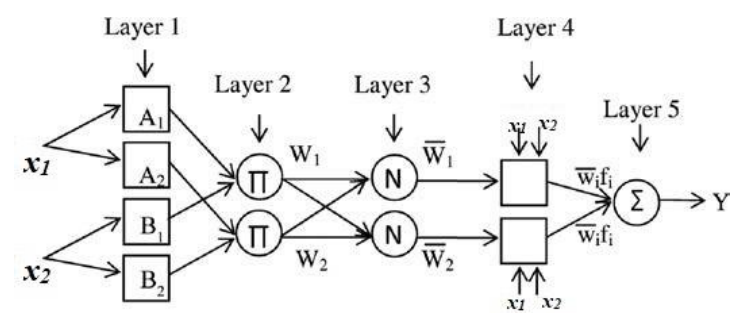

Figure 1 ANFIS architecture of two inputs and single output (Jang, 1997).

Primary layer of ANFIS model includes versatile nodes these nodes have its own functions and is represented by Equation (3).

$$
Q_{1, i}=\mu_{A}\left(x_{1}\right), \text { for } i=1,2 \text { or } Q_{1, i}=\mu_{B}\left(x_{2}\right), \text { for } i=3,4
$$


In this $\mathrm{x}_{1}, \mathrm{x}_{2}$ are process parameters, and $\mathrm{A}_{\mathrm{i}}$ and $\mathrm{B}_{\mathrm{i}}$ are membership functions for the node. $Q_{1 i}$ is the membership grade of a fuzzy set $\mathrm{A}\left(=\mathrm{A}_{1}, \mathrm{~A}_{2}, \mathrm{~B}_{1}\right.$ or $\left.\mathrm{B}_{2}\right)$ to define the applied degree of input. Second layer of ANFIS architecture have a fixed node shows the strength of the output. Output of the second layer is represented by Equation (4).

$$
Q_{2, i}=w_{i}=\mu_{A}\left(x_{1}\right) \times \mu_{B}\left(x_{2}\right), i=1,2
$$

Firing power of rules are calculated in third layer, it is a fixed node. Its $i^{\text {th }}$ node computed as a ratio of the $\mathrm{i}^{\text {th }}$ rule firing strength to the sum of all rules firing strengths and is given by Equation (5).

$$
Q_{3,1}=\vec{w}_{\iota}=\frac{w_{i}}{w_{1}+w_{2}}, i=1,2
$$

The layer four has its own function and is represented by Equation (6).

$$
Q_{4, i}=\vec{w}_{l} \times f_{i}=w_{i}\left(p i \times x_{1}+q i \times x_{2}+r\right)
$$

where $w_{i}$ is a generalized firing strength created by layer 3. pi,qi, $r$ are the node parameters. The fifth layer has fixed node and reported overall output as summation of all signals. Mathematical representation of the output is represented by Equation (7).

$$
\text { Overall output }=Q_{5, i}=\sum_{i} \overrightarrow{w_{l}} \times f_{i}=\frac{\sum_{i} \overrightarrow{w_{l}} \times f_{i}}{\sum_{i} w_{i} \times f_{i}}
$$

In a complex decision-making situation, decision-makers use a tool MCDM to achieve optimal response. In the case of conflicting criteria, VIKOR gives compromises solution to find the optimal solution in the form of VIKOR index. Since, ANFIS is a multi-input single output prediction model thus to optimize predicted response VIKOR method integrated with ANFIS names as ANFIS-VIKOR method.

Data obtained from experiments used as input in ANFIS, and after that ANFIS predicted, values were used to form decision matrix. Decision matrix was normalized using linear normalization as suggested by Opricovic and Tzeng (2004). Linear normalization is more reliable than vector normalization. Normalize matrix (D) is given by the Equation (8). Weight of the criteria affects VIKOR index, in this study equal weight are given to both criteria (MRR and $R_{a}$ ). The basic steps to find VIKOR index is same as studied by the researcher (Opricovic et al., 2004; Kumar et al.,2021). The normalization of decision matrix is given by 
D. The normalized matrix D is given by Equation (8). Where $R_{i}^{*}(k)$ is the normalized value for $\mathrm{i}^{\text {th }}$ alternative and $\mathrm{k}^{\text {th }}$ criteria.

$D=\left[R_{i}^{*}(k)\right] m \times n$

\section{EXPERIMENTAL DETAILS}

AZ-91 magnesium alloy was procured in the form of slab of dimensions $40 \mathrm{~mm} \times 40 \mathrm{~mm} \times$ $100 \mathrm{~mm}$ and the chemical compositions were determined using spark-spectro analysis method as shown in Table 1.

Table 1 Basic chemical composition of Mg-AZ91 Alloy.

\begin{tabular}{|l|l|l|l|l|l|l|}
\hline Elements & Al & Mn & $\mathbf{Z n}$ & $\mathbf{S i}$ & $\mathbf{C u}$ & $\mathbf{N i}$ \\
\hline Percentage & $8.93 \%$ & $0.21 \%$ & $0.64 \%$ & $0.017 \%$ & $0.009 \%$ & $0.002 \%$ \\
\hline
\end{tabular}

Specimens ware cut from the slab in the dimensions of $15 \mathrm{~mm} \times 15 \mathrm{~mm} \times 8 \mathrm{~mm}$ using wire-EDM (WEDM). To makes a proper contact between tool and work-piece and also to reduce error in machining, the work-piece surface was polished using polishing papers. Five controllable factors (process parameters) viz. polarity, peak current, pulse-on-time, pulse-off-time and tool electrodes are used to perform experiments (Table 2). All other parameters such as voltage, fluid pressure, EDM oil temperature etc. are considered as constant. In this work, Taguchi mixed design $L_{18}$ design of experiments (DOE) was use to perform experiment runs. Experimental runs in the uncoded form are given in Table 3.

Table 2 Independent process parameters matrix with their respective levels.

\begin{tabular}{|l|l|l|l|l|}
\hline Process parameters & Unit & Level 1 & Level 2 & Level 3 \\
\hline Polarity & & Negative $(\mathrm{N})$ & Positive $(\mathrm{P})$ & \\
\hline Peak-Current $\left(I_{p}\right)$ & $\mathrm{A}$ & 4 & 5 & 6 \\
\hline Pulse-on-Time $\left(T_{\text {on }}\right)$ & $\mu \mathrm{s}$ & 30 & 40 & 50 \\
\hline Pulse-off-time $\left(T_{\text {off }}\right)$ & $\mu \mathrm{s}$ & 20 & 25 & 30 \\
\hline Tool material & & $\mathrm{Cu}$ & $\mathrm{Gr}$ & $\mathrm{CuW}$ \\
\hline
\end{tabular}




\section{RESULTS AND DISCUSSION}

MRR is a desired response and requires maximum in machining using EDM and is given in

Table 3. To find the effect of process parameters on MRR, $\mathrm{S} / \mathrm{N}$ ration was calculated using Equation (9). MRR follows "larger the batter" criteria and large value of $\mathrm{S} / \mathrm{N}$ ratio gives optimum value of MRR (Kumar et al., 2020).

$$
S / N=-10 \times \log \left(\frac{1}{n} \sum \frac{1}{Y^{2}}\right)
$$

Table 3 Response table for MRR and $R_{a}$ with independent process parameters.

\begin{tabular}{|c|c|c|c|c|c|c|c|}
\hline S.No. & Polarity & $\boldsymbol{I}_{\boldsymbol{p}}(\mathbf{A})$ & $\boldsymbol{T}_{\boldsymbol{o n}}(\boldsymbol{\mu} \mathbf{s})$ & $\boldsymbol{T}_{\text {off }}(\boldsymbol{\mu} \mathbf{s})$ & Tool & MRR $(\mathbf{g} / \mathbf{m i n})$ & $\boldsymbol{R}_{\boldsymbol{a}}(\boldsymbol{\mu m})$ \\
\hline 1 & $\mathrm{P}$ & 4 & 30 & 20 & $\mathrm{Cu}$ & 0.021 & 0.08 \\
\hline 2 & $\mathrm{P}$ & 4 & 40 & 25 & $\mathrm{CuW}$ & 0.023 & 4.7 \\
\hline 3 & $\mathrm{P}$ & 4 & 50 & 30 & $\mathrm{Gr}$ & 0.021 & 0.49 \\
\hline 4 & $\mathrm{P}$ & 5 & 30 & 20 & $\mathrm{CuW}$ & 0.025 & 4.6 \\
\hline 5 & $\mathrm{P}$ & 5 & 40 & 25 & $\mathrm{Gr}$ & 0.028 & 2.42 \\
\hline 6 & $\mathrm{P}$ & 5 & 50 & 30 & $\mathrm{Cu}$ & 0.089 & 0.39 \\
\hline 7 & $\mathrm{P}$ & 6 & 30 & 25 & $\mathrm{Cu}$ & 0.020 & 4.76 \\
\hline 8 & $\mathrm{P}$ & 6 & 40 & 30 & $\mathrm{CuW}$ & 0.022 & 4.64 \\
\hline 9 & $\mathrm{P}$ & 6 & 50 & 20 & $\mathrm{Gr}$ & 0.034 & 0.36 \\
\hline 10 & $\mathrm{~N}$ & 4 & 30 & 30 & $\mathrm{Gr}$ & 0.036 & 3.17 \\
\hline 11 & $\mathrm{~N}$ & 4 & 40 & 20 & $\mathrm{Cu}$ & 0.009 & 2.11 \\
\hline 12 & $\mathrm{~N}$ & 4 & 50 & 25 & $\mathrm{CuW}$ & 0.014 & 2.13 \\
\hline 13 & $\mathrm{~N}$ & 5 & 30 & 25 & $\mathrm{Gr}$ & 0.040 & 1.92 \\
\hline 14 & $\mathrm{~N}$ & 5 & 40 & 30 & $\mathrm{Cu}$ & 0.010 & 0.16 \\
\hline 15 & $\mathrm{~N}$ & 5 & 50 & 20 & $\mathrm{CuW}$ & 0.014 & 3.41 \\
\hline 16 & $\mathrm{~N}$ & 6 & 30 & 30 & $\mathrm{CuW}$ & 0.008 & 0.29 \\
\hline 17 & $\mathrm{~N}$ & 6 & 40 & 20 & $\mathrm{Gr}$ & 0.054 & 4.04 \\
\hline 18 & $\mathrm{~N}$ & 6 & 50 & 26 & $\mathrm{Cu}$ & 0.014 & 1.44 \\
\hline
\end{tabular}

Surface roughness of EDMed surface was measured using surface roughness tester (Time 3100) and is given in Table 4. Smaller value of $R_{a}$ is desirable in machining as it follows "lower the better" criteria, and is calculated using Equation (10).

$$
S / N=-10 \times \log \left(\frac{1}{n} \sum Y^{2}\right)
$$

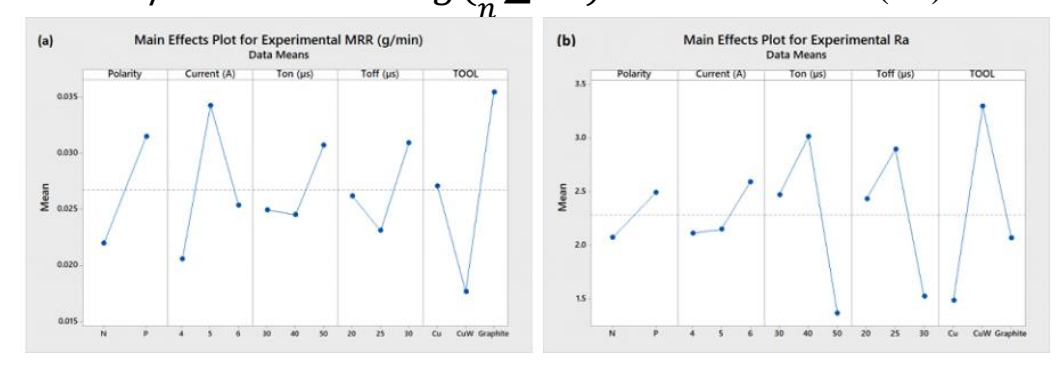

Figure 2 Main effect plots with input parameters for (a) MRR, and (b) $R_{a}$. 
$\mathrm{S} / \mathrm{N}$ ratio is a single response optimization method and used to reduce noise in MRR and $R_{a}$ measurement. Large value of $\mathrm{S} / \mathrm{N}$ ratio $(\mathrm{db})$ gives optimum value of machining response. Maximum value of MRR is $0.089(\mathrm{~g} / \mathrm{min})$ corresponds to large value of $\mathrm{S} / \mathrm{N}$ ratio $-21.03 \mathrm{db}$ (Table 4). For, minimum value of $R_{a}$ is $0.08 \mu \mathrm{m}$, corresponds to large value of $\mathrm{S} / \mathrm{N}$ ratio 21.94db. To find the effect of process parameters on response, a main effect plot for MRR and $R_{a}$, were plotted as shown in Figure 2. MRR increased as the polarity changed negative to positive due to increase in available energy in the work-piece as shown in Fig. 2(a), similar results was also reported by DiBitonto et al. (1989). On increase in $T_{o n}$, and $T_{o f f}$, MRR increased, but in case of $I_{p}$ initially MRR increased and then decreased, it is because large number of electrons restricted the motion of ions in the medium. MRR found maximum among studied tool materials when the work-piece was machined using Graphite tool (Fig. 2a), this is due to sublimation characteristics of graphite as it does not solidified on the workmaterial and always gives fresh work-surface to erode. Surface deteriorates with increase in MRR and the mean value of $R_{a}$ was found more (worst surface roughness) in case of positive polarity, and it increased with increase in $I_{p}$ due to available large amount of discharge energy which resulted uneven surface. $\mathrm{Cu}$ tool generates smoother surface as compared to $\mathrm{Gr}$ and $\mathrm{CuW}$ tool as exhibit in Fig. 2(b).

Table 4 Predicted results of MRR and $R_{a}$ with S/N ratio using ANFIS model.

\begin{tabular}{|c|c|c|c|c|c|c|c|c|}
\hline $\begin{array}{c}\text { Exp } \\
\text { No. }\end{array}$ & $\begin{array}{c}\text { Experiment } \\
\text { al MRR } \\
(\mathbf{g} / \mathbf{m i n})\end{array}$ & $\begin{array}{c}\text { Experi } \\
\text { mental } \\
\boldsymbol{R}_{\boldsymbol{a}}\end{array}$ & $\begin{array}{c}\mathbf{S} / \mathbf{N} \\
\text { ratio } \\
\text { MRR }\end{array}$ & $\begin{array}{c}\text { S/N } \\
\text { ratio } \\
\text { SR }\end{array}$ & $\begin{array}{c}\text { Predicted } \\
\text { MRR } \\
(\mathbf{g} / \mathbf{m i n})\end{array}$ & $\begin{array}{c}\text { Predicted } \\
\boldsymbol{R}_{\boldsymbol{a}}\end{array}$ & $\begin{array}{c}\text { \% } \\
\text { error } \\
\text { MRR }\end{array}$ & $\begin{array}{c}\text { \% } \\
\text { error } \\
\boldsymbol{R}_{\boldsymbol{a}}\end{array}$ \\
\hline 1 & $\mathbf{0 . 0 2 1}$ & 0.08 & -33.63 & 21.94 & 0.021 & 0.0808 & 0.05 & 1.00 \\
\hline 2 & 0.023 & 4.7 & -32.63 & -13.44 & 0.024 & 4.68 & 3.56 & 0.43 \\
\hline 3 & 0.021 & 0.49 & -33.65 & 6.20 & 0.021 & 0.497 & 0.36 & 1.43 \\
\hline 4 & 0.025 & 4.6 & -31.99 & -13.26 & 0.025 & 4.65 & 0.26 & 1.09 \\
\hline 5 & 0.028 & 2.42 & -31.03 & -7.68 & 0.029 & 2.41 & 3.20 & 0.41 \\
\hline 6 & 0.089 & 0.39 & -21.03 & 8.18 & 0.089 & 0.494 & 0.19 & 26.67 \\
\hline 7 & 0.020 & 4.76 & -33.91 & -13.55 & 0.021 & 4.78 & 2.64 & 0.42 \\
\hline 8 & 0.022 & 4.64 & -32.99 & -13.33 & 0.023 & 4.65 & 0.79 & 0.22 \\
\hline
\end{tabular}




\begin{tabular}{|c|c|c|c|c|c|c|c|c|}
\hline 9 & 0.034 & 0.36 & -29.38 & 8.87 & 0.034 & 0.365 & 0.16 & 1.39 \\
\hline 10 & 0.036 & 3.17 & -28.93 & -10.02 & 0.036 & 3.21 & 0.07 & 1.26 \\
\hline 11 & 0.009 & 2.11 & -40.72 & -6.49 & 0.009 & 2.11 & 0.68 & 0.00 \\
\hline 12 & 0.013 & 2.13 & -37.39 & -6.57 & 0.014 & 2.15 & 2.23 & 0.94 \\
\hline 13 & 0.040 & 1.92 & -27.96 & -5.67 & 0.041 & 1.93 & 2.54 & 0.52 \\
\hline 14 & 0.010 & 0.16 & -40.11 & 15.92 & 0.010 & 0.161 & 0.57 & 0.63 \\
\hline 15 & 0.014 & 3.41 & -37.24 & -10.66 & 0.014 & 3.45 & 0.28 & 1.17 \\
\hline 16 & 0.008 & 0.29 & -42.12 & 10.75 & 0.008 & 0.294 & 0.13 & 1.38 \\
\hline 17 & 0.054 & 4.04 & -25.32 & -12.13 & 0.055 & 4.04 & 0.76 & 0.00 \\
\hline 18 & 0.014 & 1.44 & -37.36 & -3.17 & 0.014 & 1.45 & 2.56 & 0.69 \\
\hline
\end{tabular}

To measure the impact of process parameters and factor level on response, a factor level analysis was performed using mean value. The large difference between factor levels shows high impact on machining response. The large value of delta means higher ranks. Process parameter ranks for MRR and $R_{a}$ are represented in Table 5. MRR are highly influenced by tool material followed by $I_{p}$, polarity, $T_{o f f}$, and $T_{o n}$. Optimal factor level for maximum MRR is the corresponding higher mean values i.e. polarity-2, $I_{p}-2, T_{o n-}-3, T_{o f f}-3$, and Tool-2. Tool materials have highest impact on $R_{a}$ followed by $T_{o n}, T_{o f f}, I_{p}$, and polarity. The optimal factor level for minimum value of $R_{a}$ is their corresponding smaller mean value, i.e. polarity-1, $I_{p}-1$, $T_{o n}-3, T_{o f f}-3$, and Tool-1.

Table 5 Impact of process parameters, and factor level on response measure.

\begin{tabular}{|c|c|c|c|c|c|}
\hline Level & Polarity & $\boldsymbol{I}_{\boldsymbol{p}}(\mathbf{A})$ & $\boldsymbol{T}_{\text {on }}(\boldsymbol{\mu s})$ & $\boldsymbol{T}_{\text {off }}(\boldsymbol{\mu s})$ & Tool \\
\hline \multicolumn{7}{|c|}{ Response mean for MRR } \\
\hline $\mathbf{1}$ & 0.02196 & 0.02057 & 0.02495 & 0.02617 & 0.02706 \\
\hline $\mathbf{2}$ & 0.03150 & 0.03427 & 0.02453 & 0.02311 & 0.03546 \\
\hline $\mathbf{3}$ & & 0.02535 & 0.03072 & 0.03091 & 0.01767 \\
\hline Delta & 0.00954 & 0.01370 & 0.00619 & 0.00780 & 0.01780 \\
\hline Rank & 3 & 2 & 5 & 4 & 1 \\
\hline \multicolumn{7}{|c|}{ Response mean for $\boldsymbol{R}_{\boldsymbol{a}}$} \\
\hline $\mathbf{1}$ & 2.074 & 2.113 & 2.470 & 2.433 & 1.490 \\
\hline $\mathbf{2}$ & 2.493 & 2.150 & 3.012 & 2.895 & 2.067 \\
\hline $\mathbf{3}$ & 0.419 & 0.475 & 1.370 & 1.523 & 3.295 \\
\hline Delta & 5 & 4 & 2 & 1.372 & 1.805 \\
\hline Rank & 5
\end{tabular}




\section{ANFIS model results}

Predicted value of MRR and $R_{a}$ are shown in Table 4. To develop ANFIS model, MATLAB Neural Network Toolbox function was used and its architecture is represented in Figure 3. The ANFIS factors and modeling parameters are illustrated in Table 6. In ANFIS model, Gaussian function with two membership function for polarity and three membership function for $I_{p}, T_{o n}, T_{o f f}$, and tool materials.

Table 6 Factors for ANFIS modeling.

\begin{tabular}{|l|c|l|l|}
\hline Parameters & Values & Parameters & Values \\
\hline Number of input & 5 & & \\
\hline Membership function & Gaussmf & $\begin{array}{l}\text { Size of training data } \\
\text { set }\end{array}$ & $18 \times 5$ \\
\hline Error Tolerance & 0.0 & Number of output 2 & 2 \\
\hline Number of epochs & 101 & Optimisation Method & Hybrid \\
\hline
\end{tabular}

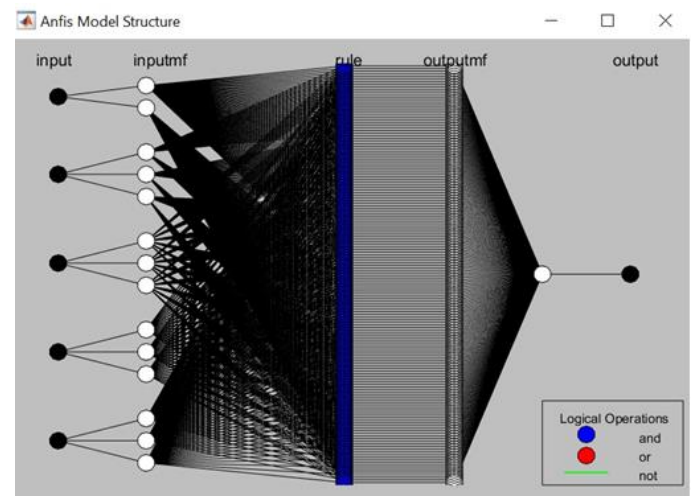

Figure 3 ANFIS model architecture with five inputs.

Relative percentage error (RE) between experimental and predicted results was calculated for MRR and $R_{a}$ using Equation (11). Calculated REs using ANFIS model were $1.17 \%$, and $2.20 \%$, for MRR, and $R_{a}$, respectively. Figure 4 shows the graph between experimental and predicted results.

$$
\text { Relative error } \%=\frac{\text { Experimental value }- \text { Model value }}{\text { Experimental value }} \times 100
$$



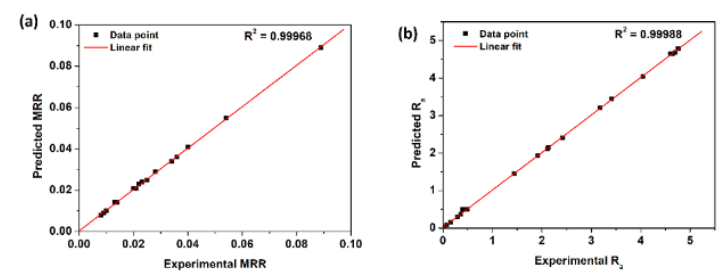

Figure 4 Graph between experimental and predicted results of (a) MRR, and (b) $R_{a}$.

The surface plot generated for MRR (Figure 5) and for $R_{a}$ (Figure 6) through ANFIS models. Increase in MRR, reduces surface roughness of machined surface, which is clearly observed in Figure 5 and 6. Fig. 5(a,b) show that MRR increased on decrease in $I_{p}$ and $T_{o n}$ at positive polarity, whereas $R_{a}$ follows opposite pattern as shown in Fig.6 (a, b). Fig. 5(c) and 6(c) exhibit that increase in $T_{\text {off }}$ reduced MRR, and increase in $R_{a}$, respectively, at positive polarity. Fig. 5(d) shows that MRR was maximum when machining is performed using graphite tool, which is also confirmed by main effect plot (Fig. 2a). Maximum surface roughness was observed when material machined with copper tool (Fig. 6d) which is also confirmed by Fig. 2(b).
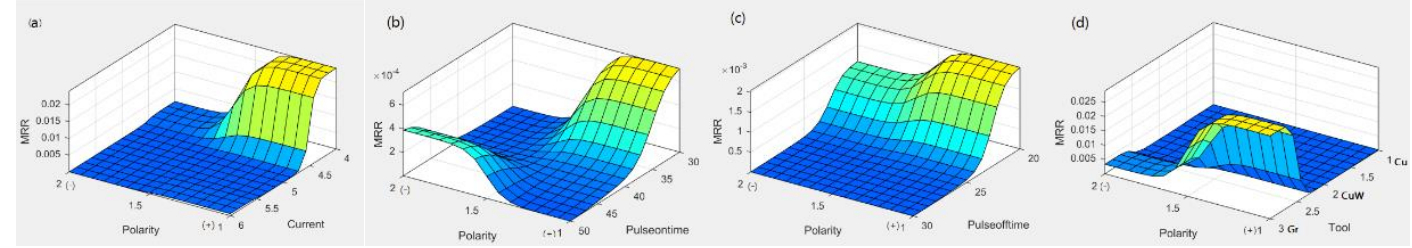

Figure. 5 Surface plots generated by ANFIS model for MRR.
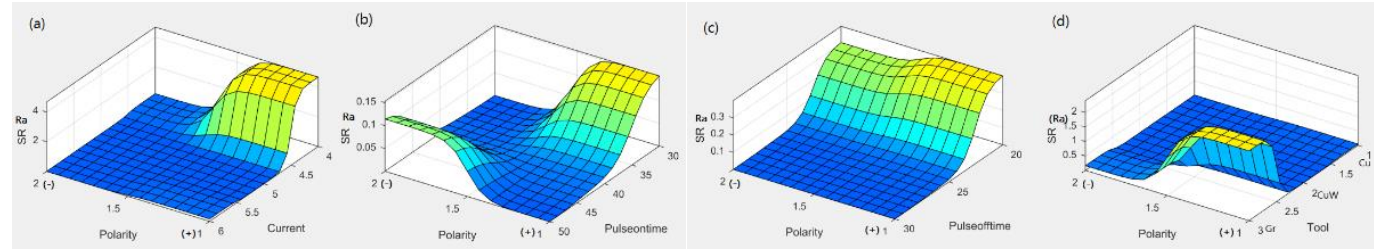

Figure 6 Surface plots generated by ANFIS model for $R_{a}$.

\section{Optimization using ANFIS-VIKOR method}

ANFIS model is used to predict the response whereas VIKOR method for optimization. In ANFIS-VIKOR method, response predicted from ANFIS model was used as an input in VIKOR method. Predicted responses were normalized to make uniformity in data. The response measure which required maximum was considered as utility measure whereas 
minimum as regret measure. Equal weight $(w=0.5)$ is given to both responses. Compromised solution for maximum MRR and minimum $R_{a}$ were calculated using ANFIS-VIKOR index $\left(Q_{i}\right)$ (Table 7).

Table 7 Results obtained from ANFIS-VIKOR method.

\begin{tabular}{|c|c|c|c|c|c|c|c|}
\hline $\begin{array}{c}\text { Exp. } \\
\text { No. }\end{array}$ & $\begin{array}{c}\text { ANFIS Predicted } \\
\text { results }\end{array}$ & \multicolumn{2}{c|}{$\begin{array}{c}\text { Normalized } \\
\text { value }\end{array}$} & $\begin{array}{c}\text { Utility } \\
\text { measure }\end{array}$ & $\begin{array}{c}\text { Regret } \\
\text { measure }\end{array}$ & $\begin{array}{c}\text { ANFIS-VIKOR } \\
\text { index }\end{array}$ \\
\hline & $\begin{array}{c}\text { MRR } \\
(\mathbf{g} / \mathbf{m i n})\end{array}$ & $\begin{array}{c}\boldsymbol{R}_{\boldsymbol{a}} \\
(\boldsymbol{\mu m})\end{array}$ & $\mathbf{M R R}$ & $\boldsymbol{R}_{\boldsymbol{a}}$ & $\boldsymbol{S}_{\boldsymbol{i}}$ & $\boldsymbol{R}_{\boldsymbol{e}}$ & $\boldsymbol{Q}_{\boldsymbol{i}}$ \\
\hline 1 & 0.021 & 0.0808 & 0.148 & 0.007 & 0.920 & 0.420 & 0.869 \\
\hline 2 & 0.024 & 4.68 & 0.173 & 0.385 & 0.409 & 0.489 & 0.575 \\
\hline 3 & 0.021 & 0.497 & 0.148 & 0.041 & 0.876 & 0.420 & 0.838 \\
\hline 4 & 0.025 & 4.65 & 0.180 & 0.382 & 0.406 & 0.486 & 0.570 \\
\hline 5 & 0.029 & 2.41 & 0.207 & 0.198 & 0.621 & 0.369 & 0.597 \\
\hline 6 & 0.089 & 0.494 & 0.632 & 0.041 & 0.456 & 0.044 & 0.121 \\
\hline 7 & 0.021 & 4.78 & 0.148 & 0.393 & 0.420 & 0.500 & 0.595 \\
\hline 8 & 0.023 & 4.65 & 0.161 & 0.382 & 0.422 & 0.486 & 0.581 \\
\hline 9 & 0.034 & 0.365 & 0.242 & 0.030 & 0.808 & 0.339 & 0.700 \\
\hline 10 & 0.036 & 3.21 & 0.256 & 0.264 & 0.494 & 0.333 & 0.465 \\
\hline 11 & 0.009 & 2.11 & 0.066 & 0.173 & 0.775 & 0.491 & 0.843 \\
\hline 12 & 0.014 & 2.15 & 0.099 & 0.177 & 0.743 & 0.463 & 0.789 \\
\hline 13 & 0.041 & 1.93 & 0.293 & 0.159 & 0.598 & 0.295 & 0.499 \\
\hline 14 & 0.010 & 0.161 & 0.071 & 0.013 & 0.979 & 0.487 & 0.986 \\
\hline 15 & 0.014 & 3.45 & 0.098 & 0.284 & 0.605 & 0.464 & 0.689 \\
\hline 16 & 0.008 & 0.294 & 0.056 & 0.024 & 0.977 & 0.500 & 0.999 \\
\hline 17 & 0.055 & 4.04 & 0.390 & 0.332 & 0.289 & 0.421 & 0.414 \\
\hline 18 & 0.014 & 1.45 & 0.099 & 0.119 & 0.817 & 0.145 & 0.842 \\
\hline
\end{tabular}

In ANFIS-VIKOR index, experiment having $Q_{i}$ value near to zero is highest rank, and represents best combination of result. In this study experiment number 6 is best ranked by $Q_{i}$. A confirmation test was performed on optimal factor level given by ANFIS-VIKOR method. Results of confirmation test are listed in Table 8.

Table 8 Confirmation test result on optimal factor level.

\begin{tabular}{|c|c|c|c|c|c|c|}
\hline \multicolumn{4}{|c|}{ Optimal process parameters } & \multicolumn{2}{c|}{ Experimental Result } \\
\hline Polarity & $I_{p}$ & $T_{o n}$ & $T_{\text {off }}$ & Tool & MRR $(\mathrm{g} / \mathrm{min})$ & $R_{a}(\mu \mathrm{m})$ \\
\hline $\mathrm{P}(+)$ & 5 & 50 & 25 & $\mathrm{CuW}$ & 0.072 & 0.160 \\
\hline
\end{tabular}




\section{CONCLUSIONS}

Five process parameters (polarity, $I_{p}, T_{o n}, T_{\text {off }}$, and tool) were used for machining AZ 91 alloy using Taguchi mixed design $\mathrm{L}_{18}$ DOE to evaluate response parameters MRR and $R_{a}$. ANFISVIKOR method was used to predict and optimize the responses. The following conclusion was drawn from this study.

- Maximum MRR $(0.089 \mathrm{~g} / \mathrm{min})$ was found at positive polarity, $I_{p^{-}}-5 \mathrm{~A}, T_{\text {on }}-50 \mu \mathrm{s}, T_{\text {off }}$ $30 \mu \mathrm{s}$, and $\mathrm{Cu}$ tool and minimum $R_{a}(0.08 \mu \mathrm{m})$ was at parameters positive polarity, $I_{p^{-}}$ $4 \mathrm{~A}, T_{\text {on }}-30 \mu \mathrm{s}, T_{\text {off }}-20 \mu \mathrm{s}$, and $\mathrm{Cu}$ tool. These results were also confirmed by the single response optimization tool $\mathrm{S} / \mathrm{N}$ ratio. Factor level analysis showed that tool materials have highest impact on the MRR and $R_{a}$.

- $\quad$ The ANFIS model was successfully developed for MRR and $R_{a}$ and developed model gives an accuracy of $98.83 \%$, and $97.80 \%$, for MRR, and $R_{a}$, respectively.

- The multi response optimization ANFIS-VIKOR method was successfully developed and gave compromise solution for MRR and $R_{a}$ corresponding to minimum ANFISVIKOR index $\left(Q_{i}\right)$. This method shows experiment number 6 has best rank.

\section{REFERENCES}

Ali, Y., Qiu, D., Jiang, B., Pan, F., \& Zhang, M.X. 2015. Current research progress in grain refinement of cast magnesium alloys: A review article. J. Alloys Compd. 619:639-651.

Amorim, F.L., \& Weingaertner, W.L. 2005. The influence of generator actuation mode and process parameters on the performance of finish EDM of a tool steel. J. Mater. Process. Technol. 166:411416.

Bhaumik, M., \& Maity, K. 2018. Effect of different tool materials during EDM performance of titanium grade 6 alloy. Int. J. Eng. Sci. Technol. 21:507-516.

DiBitonto, D.D., Eubank, M.R., Patel, P.T., \& Barrufet, M.A. 1989. Theoretical models of the electrical discharge machining process I A simple cathode erosion model. Int. J. Appl. Phys. 66:4095-4103.

Dhaker, K.L., Singh, B., \& Shrivastava, Y. 2019. Adaptive neuro fuzzy inference system based modeling of recast layer thickness during laser trepanning of Inconel718 sheet. J. Braz. Soc. Mech. Sci. \& Eng. 41:423. 
Ho, K.H., \& Newman, S.T. 2003. State of the art electrical discharge machining (EDM). Int. J. Mach. Tools Manuf. 43:1287-1300.

Jang, J.S.R. 1993. ANFIS adaptive-network-based fuzzy inference system. IEEE Transactions on Systems Man and Cybernetics 23(3):665-685.

Jang, J.S.R. 1997. ANFIS architecture. In Neuro-fuzzy and soft computing, Hoboken, NJ: John Wiley and Sons.

Khan, F., Kumar, J., \& Soota, T. 2020. Optimization of EDM process parameter for stainless steel D3. Mater. Today Proc. 25:635-638.

Kumar, S., Dhanabalan, S., \& Narayanan, C.S. 2020. Application of ANFIS and GRA for multiobjective optimization of optimal wireEDM parameters while machining Ti6Al4V alloy. SN Applied Sci. https://doi.org/10.1007/s42452-019-0195-Z

Kumar, A., Kumar, J., \& Soota, T. 2018. Optimisation of wire-cut EDM process parameter by Grey-based response surface methodology. J. Ind. Eng. Int. 14:821-829.

Kumar, A., Maheshwari, S., Sharma, C., Beri, N. 2010. A study of multi objective parametric optimization of silicon abrasive mixed electrical discharge machining of tool steel. Mater. Manuf. Process. 25:1041-1047.

Kumar, J., Soota, T., Rajput, S.K., Saxena, K.K. 2021. Machining and optimization of Zircaloy-2 using different tool electrodes. Mater. Manuf. Process. doi.org/10.1080/10426914.2021.1905829.

Lee, S.H., \& Li, X.P. 2001. Study of the effect of machining parameters on the machining characteristics in electrical discharge machining of tungsten carbide. J. Mater. Process. Technol. 115(3): 344-358.

Li, L., Wong, Y.S., Fuh, J.Y.H., \& Lu, L. 2002. EDM performance of TiCr copper-based sintered electrodes. Mater. Des. 22(8):669-678.

Li, S.H., \& Li, X. 2003. Study of the surface integrity of the machined workpiece in the EDM of tungsten carbide. J. Mater. Process Technol. 139:315-321.

Luo, K., Zhang, L., Wu, G., Liu, W., \& Ding, W. 2019. Effect of $Y$ and Gd content on the microstructure and mechanical properties of MgYRE alloys. J. Magnes. Alloy. 7:345-354.

Maher, Ib., Ling, L.H., Sarhan, A.A.D., \& Hamdi, M. 2015. 8th Vienna International Conference on Mathematical Modelling. Mathematical Modelling. Vienna University of Technology, Vienna: Austria.

Manikandan, N., Balasubramanian, K., Palanisamy, D., Gopal, P.M., Arulkirubakaran, D., \& Binoj, J.S. 2019. Machinability Analysis and ANFIS modelling on Advanced Machining of Hybrid Metal Matrix Composites for Aerospace Applications. Mater. Manuf. Process. 34(16):1866-1881.

Opricovic, S., \& Tzeng, G. H. 2004. Compromise solution by MCDM methods A comparative analysis of VIKOR and TOPSIS. Eur. J. Oper. 156:445-455. 
Ramaswamy, A., \& Perumal, A.V. 2020. Multiobjective optimization of drilling EDM process parameters of LM13 Al alloy10ZrB25TiC hybrid composite using RSM. J. Braz. Soc. Mech. Sci. \& Eng. 42:432.

Razak, M.A., Rani, M.A., Rao, T.V.V.L.N., Pedapati, S.R., \& Kamal, S. 2016. Electrical Discharge Machining on Biodegradable AZ31 Magnesium Alloy using Taguchi method. Procedia Eng.148: 916-922.

Rodic, D., Gostimirovic, M., Sekulic, M., Aleksic, A., \& Madic, M. 2020. Application of ANFIS for modeling and predicting the EDM surface roughness. 19th International Symposium INFOTEHJAHORINA.

Singaravel, B., Prasad, S.D., Shekar, K.C., Rao, K.M., \& Reddy, G.G. 2020. Optimization of process parameters using hybrid Taguchi and VIKOR Method in electrical discharge machining process. Adv. Intell. Syst. 949:527-537.

Singh, N.K., Singh, Y., Kumar, S., \& Upadhyay, R. 2020. Integration of GA and neuro fuzzy approaches for the predictive analysis of gas assisted EDM responses. SN Appl. Sci. 2:137.

Song, J., She, J., Chen, D., et al. 2020. Latest research advances on magnesium and magnesium alloys worldwide. J. Magnes. Alloy. 8:141.

Tong, L.I., Chen, C.C., \& Wang, C.H. 2007. Optimization of multi response processes using the VIKOR method. Int. J. Adv. Manuf. Technol. 31:1049-1057.

Yeganeh, M., \& Mohammadi, N. 2018. Superhydrophobic surface of Mg alloys: A review. J.Magnes. Alloy. 6:59-70.

Zhang, Y., Zheng, Y.X., Xing, J., \& Zhu, D. 2016. Effect of tube electrode inner diameter on electrochemical discharge machining of nickel-based superalloy. Chinese J. Aeronaut. 29:(4)11031110. 